\title{
Deterioro ambiental, una propuesta conceptual para zonas rurales de México
}

Rosalva Landa, Julia Carabias y Jorge Meave Laboratorio de Ecología, Facultad de Ciencias Universidad Nacional Autónoma de México

Resumen

Continuamente se hace referencia a la pérdida de recursos naturales y al deterioro ambiental; sin embargo, conceptos tales como degradación de la tierra, deterioro y desertificación son ideas que se sobreentienden en los discursos ambientalistas. El significado de estos términos supone la aplicación de los mismos en diferentes escalas de aproximación y distintos ambientes; no obstante, no están definidos claramente en forma individual, ni en la relación que guardan entre sí. El hecho de que tales conceptos sean vagos, se usen como sinónimos o presenten múltiples facetas, tiene consecuencias cuando se pretende hacer una evaluación del proceso, ya que también se vuelven vagos los elementos del ambiente que hay que tomar en cuenta para caracterizar la degradación.

Este ensayo recopila diferentes ideas que se han planteado en los últimos años en torno al concepto de deterioro ambiental y su aplicación en áreas rurales. Se revisan Ios estudios que algunos autores han realizado para evaluar este fenómeno directa $\mathrm{o}$ indirectamente, y sus posibles relaciones con 
elementos socioeconómicos. Se propone una definición y una clasificación del proceso de deterioro ambiental, basadas en un estudio de caso desarrollado en la región de La Montaña de Guerrero, el cual se explica brevemente.

\section{Los principales conceptos}

Actualmente se habla poco sobre la definición del deterioro puramente biológico, más bien se discute como un proceso inmerso en la dinámica de la crisis ambiental global. Es importante entender la idea en un contexto biológico, ya que el problema ambiental contemporáneo, independientemente de la incidencia política, social y económica, tiene fundamentalmente carácter biológico; y aunque definirlo es útil, no debe concebirse como un proceso independiente y aislado de la sociedad humana.

En México la primera discusión sobre "deterioración ambiental" fue editada por el Instituto Mexicano de Recursos Naturales Renovables (Beltrán, 1971). Más tarde, Ortiz, Anaya y Estrada (1994) aclaran algunos conceptos y aproximaciones metodológicas relativas a la degradación de la tierra con énfasis en aspectos edáficos.

El deterioro ecológico está relacionado con una disminución en la cantidad y disponibilidad de energía utilizada por los organismos en funciones tales como: alimentación, crecimiento, reproducción y defensa. Bolaños (1990) denomina "impacto biológico $^{\mathrm{n}}$ a "toda acción humana que reduzca la adecuación de los organismos de la biósfera".

Bradshaw, Goode y Thorp (1986) consideran a un ecosistema degradado como aquel en el que se reduce la entrada de energía o se incrementa la pérdida de energía por causas humanas o naturales. McGovern et al. (1988) conceptúan la degradación ambiental como una alteración en los ecosistemas que reduce de manera efectiva la productividad de la tierra. Graham (1992) define la degradación como una disminución en la condición o calidad de la tierra como consecuencia de su uso, y relaciona directamente a las actividades productivas con el deterioro ambiental.

Por su parte, Bilsborrow y Okoth-Ogendo (1992) junto con Bilsborrow y DeLargy (1991) reconocen tres tendencias ambientales en áreas rurales relacionadas con el detertoro: deforestación, desertificación y erosión del suelo, ejemplificando con casos en América Latina y en África. Mencionan que los procesos demográficos influyen en el deterioro ambiental mediante variables que intervienen en el uso de la cierra, pero sin atribuir relaciones directas (Bilsborrow, 1993).

El fenómeno de desertificación se asocia frecuentemente con deterioro. Inicialmente se consideraba como un proceso indicador de patrones de uso y "degradación" de la vegetación original (Glantz, 1977), que consistía en la expansión de las condiciones desérticas por acción antrópica sobre ecosistemas frágiles en condiciones climáticas adversas (CEPAL-CLADES, 1981). Este concepto atribuye de manera directa la degradación a la acción humana. Cabe destacar que en términos del deterioro ambiental no se trata de la expansión o creación de ecosistemas desérticos - los cuales son ricos en diversidad y mantienen una dinámica ecológica muy compleja-, sino de la transformación de ecosistemas originales, lo que implica empobrecimiento de sus propiedades físicas y funcionales.

Olsson y Rapp (1991) aclaran que cuando la degradación es severa, puede ser considerada como una desertificación. Esta última es resultado de la combinación de factores climáticos (principalmente sequía) y factores antropogénicos (principalmente sobreutilización). Los autores ejemplifican la idea con datos de la sequía de 1982 a 1984 en la provincia de Kordofan en Sudán Central, la cual se caracterizó por la pérdida total de cultivos y de vegetación., erosión, mortalidad de pobladores y de animales domésticos, y migración humana. Este trabajo permite reflexionar sobre la relación de las condiciones de la población humana y las del ambiente, ya que aparentemente una condición natural promueve cambios socioeconómicos y demográficos muy fuertes. En este sentido, García-Barrios, García-Barrios y Alvarez Buylla (1991) explican cómo las diferentes formas de organización social ejercen influencia en la manera de enfrentar las crisis ambientales en comunidades campesinas.

De acuerdo con Ortiz, Anaya y Estrada (1994), la degradación de la tierra es un sinónimo de desertificación, definida como "la disminución o destrucción del potencial biológico de los recursos naturales ocasionado por el mal uso y manejo de los mismos, lo que trae como consecuencia procesos degenerativos del medio físico, económico y social de las poblaciones involucradas y su entorno". 
Actualmente se hace referencia a la desertificación como la degradación de la tierra en zonas áridas, semiáridas y secas-subhúmedas, resultado básicamente de un impacto humano adverso, definición que es adoptada por el United Nations Environmental Programme (UNEP) en 1991 (UNEP, 1992), y en México por la Comisión Nacional de Zonas Áridas (SEDESOLCONAZA, 1994).

La degradación también se relaciona con ideas como la pérdida de calidad ambiental, el estrés ecológico, la perturbación, la fragmentación y el empobrecimiento biótico, entre otras.

\section{Vinculación del deterioro con aspectos socioeconómicos}

Se ha tratado de explicar la relación entre el ambiente y los elementos socioeconómicos desde perspectivas económicas o demográficas. Generalmente se asocia la degradación de la tierra con el crecimiento de las poblaciones humanas y el desarrollo (Arrhenius, 1992; Izazola y Lerner, 1993; Arizpe, Stone y Major, 1994); sin embargo, algunos autores toman en cuenta el sobreconsumo, la dependencia de tecnología moderna, el desigua acceso a los recursos, y la pobreza, entre otros factores, como determinantes de la crisis ambiental.

Blaikie y Brookfield (1987) explican que la degradación ambiental es por definición un problema social, ya que los procesos ambientales ocurren con o sin interferencia humana, y tales fenómenos son entonces considerados como "degradación ${ }^{\mathrm{n}}$ cuando se perciben con un criterio social relacionado con uso actual y potencial de la tierra. También identifican tres características básicas de la relación entre degradación de la tierra y sociedad: $\boldsymbol{i}$ ) el efecto interactivo de degradación y sociedad a través del tiempo; ii) la escala geográfica y de organización social y política; y iii) las contradicciones entre cambios sociales y ambientales; no consideran relaciones simples entre sociedad y naturaleza.

Le Tacon y Laker (1990) analizan las principales causas de deforestación tropical, destacando la fragilidad natural de los ecosistemas y los efectos de cambios climáticos. Especialmente consideran que en los países en desarrollo la presión del incremento de la población y la creciente demanda de los países desarrollados sobre los ecosistemas tropicales son determinantes en las tasas de deforestación. Para Rubenson (1991) la interacción entre estrés ambiental e inestabilidad social y política puede ser postulada aunque las relaciones son muy complejas. Por su parte, Ehui y Hertel (1992) proponen una interrelación entre la deforestación y la productividad agrícola.

Se ha analizado el problema de degradación de la tierra desde una perspectiva económica, con particular atención a la situación de los países en desarrollo. En este enfoque la degradación significa una pérdida de capacidad productiva del ambiente a consecuencia de procesos tales como erosión, salinización, pérdida de nutrientes, pérdida de la estructura del suelo, y contaminación (Bojö, 1991).

También se han discutido las diferencias en tendencias poblacionales entre países más y menos desarrollados, las cuales están estrechamente vinculadas con tres factores demográficos: fecundidad, mortalidad y migración. Se mencionan como efectos colaterales a la degradación del paisaje, el incremento de la marginación y la pobreza en los países del Tercer Mundo (Falkenmark y Suprapto, 1992). Para Myers (1992) el crecimiento poblacional que interactúa con tecnologías y políticas de desarrollo inadecuadas, resulta en explotación que rebasa el potencial óptimo del ambiente.

Bilsborrow y Okoth-Ogendo (1992) explican que la degradación puede ser más o menos severa dependiendo del régimen de tenencia, que a su vez determina el acceso a la tierra en una sociedad, el nivel de tecnología y las politicas ambientales. Estos autores concluyen que no existe una téoría que pueda explicar adecuadamente la compleja interacción entre el crecimiento de la población y los cambios en el uso de la tierra, de manera que sugieren investigar los patrones de uso de la tierra en etapas particulares de la transición demográfica (sensu Thompson, 1930, citado en Davis, 1991).

Particularmente en la República de Korea se ha experimentado una rápida transición demográfica, y la degradación de sus recursos naturales ha sido más severa cuando el crecimiento poblacional es menor, ya que se han adoptado estilos de vida incompatiblescon el uso sostenido del medio. Kim y van den Oever (1992) atribuyen esto al cambio de patrones de consumo y estilos de vida, aunque también puede asociarse con un efecto acumulativo sobre el ambiente, entre otros factores.

Cruz et al. (1992) analizan la manera en que la pobreza y las políticas de tenencia de la tierra están ligadas al estrés ambiental, y éste es asociado también con crecimiento y migración humana en Filipinas y Costa Rica. A su vez, las condiciones de pobreza pueden establecer un ciclo de degradación ambiental si los "pobßs" son 
forzados por necesidades inmediatas a usar los recursos intensivamente y eventualmente a degradarlos. Esta idea es discutida también por Browne (1982) y Pearce (1990); para ellos la pobreza no es un problema relacionado'con recursos inadecuados, sino con el mal uso de los mismos, situación que es perpetuada por las desigualdades sociales y balanceada por presiones externas sobre los recursos del medio rural. Consideran que el crecimiento de las poblaciones humanas impone presiones cobre los recursos, y que la pobreza limita la capacidad para invertir en una producción sustentable, de manera que la pobreza "no es una causa de la degradación ambiental, sino el mecanismo mediante el cual las verdaderas causas subyacentes se transforman en acciones que degradan el medio [...] resulta ser un factor agravante del proceso de degradación ambiental". A su v a, el crecimiento de la población actúa como agravante y causa principal del deterioro, aunque en otro aspecto promueve el cambio tecnológico. Pearce (1990) señala igualmente que el nexo entre pobrezay degradación puede analizarse en relación con la distribución geográfica de la pobreza rural, que usualmente se localiza en áreas ecológicamente frágiles. Un análisis similar es discutido por Boserup (1981) y Dasgupta (1992).

En nuestro país existen pocas aproximaciones en la estimación del estado actual de degradación.delos recursos naturales que incluyan la visión ecológica y la influencia de las actividades humanas. Provencio y Carabias (1993) explican que el daño al ambiente no se puede atribuir a un factor determinado y que es difícil establecer una relación causa-efecto entre deterioro y migración o pobreza rural. Consideran que no todas las formas de deterioro están generadas por presión demográfica y que no es posible generalizar la idea de que la pobreza tenga una relación directa con el deterioro ambiental. Para ellos las condiciones económicas desfavorables no pueden ser ignoradas al evaluar las determinantes del deterioro ambiental.

\section{Vías metodológicas para la caracterización del deterioro} ambiental

Aunque el desarrollo conceptual del tema tiene avances importantes, las definiciones planteadas sobre degradación ambiental son difíciles de llevar a la práctica; las investigaciones son escasas y los resultados actuales son inadecuados o parciales como para formular lineamientos de políticas. Dada la complejidad del problema, es recomendable abordar la degradación en escalas de espacio y tiempo, ya que se trata de variables fundamentales en la mayoría de los programas de manejo de recursos (Fox, 1992; Helldén, 1991; Jean y Bouchard, 1991; Landa, Meave y Carabias, 1997).

Los trabajos enfocados a la estimación del deterioro ambiental desde el punto de vista físico son escasos, y los estudios que han relacionado las condiciones de daño del medio natural con factores socioeconómicos son relativamente recientes; la mayoría de ellos se dan a conocer a partir de 1987, otros no están sistematizados o se encuentran aún en la fase de definición del problema y en la búsqueda de metodologías óptimas que permitan caracterizar la dinámica de la degradación. Por otra parte, existen varios estudios desde la perspectiva ecológica que discuten la necesidad de realizar enfoques interdisciplinarios en la problemática ambiental de algunas zonas rurales, incluyendo en sus definiciones la influencia humana sobre el ambiente.

Muchos de los problemas metodológicos surgen por la dificultad para delimitar el punto en el que termina la alteración y el momento en el que empieza el daño a los recursos naturales (Landa, 1992) en un sentido de disminución de sus propiedades, como lo definen Glantz (1977), Bradshaw, Goode y Thorp (1986), McGovern et al. (1988), Boj6 (1991), Helldén (1991), Olsson y Rapp (1991), Bilsborrow y Okoth-Ogendo (1992), y Graham (1992).

De acuerdo con los conceptos mencionados previamente, el deterioro ecológico debería medirse principalmente en términos energéticos, es decir, estimar la cantidad de energía que entra y sale de los ecosistemas y cuantificar también la disminución de la energía disponible para que los organismos realicen sus funciones básicas, tanto a nivel de comunidades como de ecosistemas. Otra variable importante a considerar es la pérdida o disminución de elementos del sistema, como la diversidad animal y vegetal, los hábitats para la vida silvestre que pueden perderse por erosión, salinización, contaminación, disminución del tamaño de las áreas naturales y decremento de la productividad primaria. La pérdida de estructura o del grado de naturalidad de los ecosistemas, así como la fragmentación del paisaje y del hábitat, son igualmente importantes (Committee on the Applications of Ecological Theory to Environmental Problems, 1986; Forman y Godron, 1981 y 1984; Naveh y Lieberman, 1984; Noss, 1987; Spellerberg, 1981; Sharitz et al. 1992; Aizen y Feizinger, 1994). También se puede evaluar cuantificando variables que restringen la producción fotosintética 
(estrés ecológico), así como la destrucción total o parcial de biomasa (perturbación).

Estos criterios de caracterización son los que de manera ideal deberían emplearse en evaluaciones ecológicas del deterioro. Sin embargo, la urgencia de contar con indicadores confiables y la tecnología e infraestructura disponibles en países en desarrollo, limitan enormemente la estimación de flujos energéticos o la adecuación biológica; y mucho menos a escalas de paisaje, regiones o unidades terrestres. Es por esto que se han desarrollado otras vías metodológicas para caracterizar y evaluar el deterioro, que permiten detectar tendencias generales y caracterizar procesos gracias a ciertos indicadores biológicos como: la productividad, erosión, salinidad y acidez del suelo; pérdida de estructura de éste; deforestación y regeneración; entre otros. En este sentido los trabajos de Helldén (1991), Jean y Bouchard (1991), Chokor y Mene (1992), y Graham (1992), evalúan la degradación ambiental y los cambios en patrones de uso por medio de sensores remotos, especialmente con fotografías aéreas en diferentes tiempos. Mehrotra, Yadav y Adinarayana (1991) se basan,en técnicas de interpretación visual de imágenes Landsat para estimar cambios en la cobertura vegetal. Landa, Meave y Carabias (1997) evalúan la degradación ambiental a nivel regional con ayuda de sensores remotos, identificando tres elementos: alteración, daño y riesgo. Helldén (1991), Jean y Bouchard (1991), y Lira et al. (1992), utilizan imágenes de satélite, integradas con sistemas de información geográfica (SIG) y modelaje espacial, obteniendo mapas de productividad de diferentes sistemas. Con estas mismas herramientas Toledo (1994) estima la relación que existe entre alteración y regeneración, y el papel que juega la distancia de los poblados en la conservación de los ecosistemas. Por su parte, Mladenoff et al. (1993), con un enfoque paisajístico, determinan el efecto de la actividad humana sobre los patrones espaciales de los bosques, con ayuda de SIG. Spies, Ripple y Bradshaw (1994) estiman tasas y patrones de perturbación en paisajes fragmentados con imágenes Landsat, y determinan la densidad y calidad de las masas boscosas.

\section{Definición y clasificación del deterioro ambiental, el caso de La} Montaña de Guerrero

En este apartado se presenta brevemente el desarrollo de una investigación para caracterizar el deterioro ambiental en áreas rurales, particularmente en la región de La Montaña de Guerrero, en México, y la manera en que a partir de este estudio se precisa la definición y se clasifica entonces el proceso de deterioro ambiemal. El trabajo forma parte de una investigación más amplia que enfoca la explicación del papel que juegan las condiciones socioeconómicas y productivas en la dinámica regional del deterioro a través del tiempo. Aquí sólo se presentarán los resultados de la parte ecológica.

La región de La Montaña de Guerrero se localiza en la parte oriental del estado (fig. 1), entre los paralelos $16^{\circ} 52^{\prime}$ y $18^{\circ} 08^{\prime}$ de latitud norte, y los meridianos $98^{\circ} 12^{\prime}$ y $99^{\circ} 30^{\prime}$. Colinda al norte con el estado de Puebla, al este con Oaxaca, al sur con la Costa Chica de Guerrero y al oeste con la región central del estado. La zona de estudio abarca aproximadamente 17 municipios que cubren en conjunto $6,530 \mathrm{~km}^{2}$ (Landa, Meave y Carabias, 1997).

Comprende una zona cálida-subhúmeda en la porción norte, y otra templada-subhúmeda en el sur. El régimen de lluvias es en verano con precipitaciones entre los 750 y los 2,500 mm anuales. $\mathrm{La}$ temperatura media anual fluctúa entre 16 y $23^{\circ} \mathrm{C}$. Ubicada en la cuenca del río Balsas de la Sierra Madre del Sur, es una región constituida principalmente por sistemas de sierra alta compleja, Comprende altitudes de 700 a 3,060 m.s.n.m. Destacan comunidades vegetales de selva baja caducifolia, encinares y bosques de pino (Toledo, 1994; PAIR, 1992).

En la región prevalecen condiciones de vida precarias para los pobladores, en su mayoría indígenas mixtecos, nahuas y tlapanecos (Martínez y Obregón, 1991), a la vez que las tierras productivas se agotan y degradan. La marginación se expresa en mínimos servicios de salud, comunicación inadecuada, educación deficiente, gasto público insuficiente y falta de apoyo agropecuario (Carabias, Provencio y Toledo, 1994; Martínez y Obregón, 1991; Provencio y Carabias, 1993)

El deterioro ambiental se refleja como deforestación y erosión del suelo, debidas en parte al uso intensivo del medio y a formas de aprovechamiento desfavorables que acentúan el riesgo natural de pérdida de recursos, aunados al agotamiento de cuerpos de agua y a la pérdida de fertilidad de suelo. Se ha pretendido responsabilizar al crecimiento de las poblaciones indígenas de esta región como causantes del deterioro de sus recursos naturales, sin tomar en cuenta el conjunto de factores que han condicionado la forma de uso del ambiente y olvidando que se trata de la base de subsistencia de las comunidades indígenas, así como de su único patrimonio. Se cree que las condiciones de pobreza y marginación 
Figura 1

Región de La Montaña de Guerrero

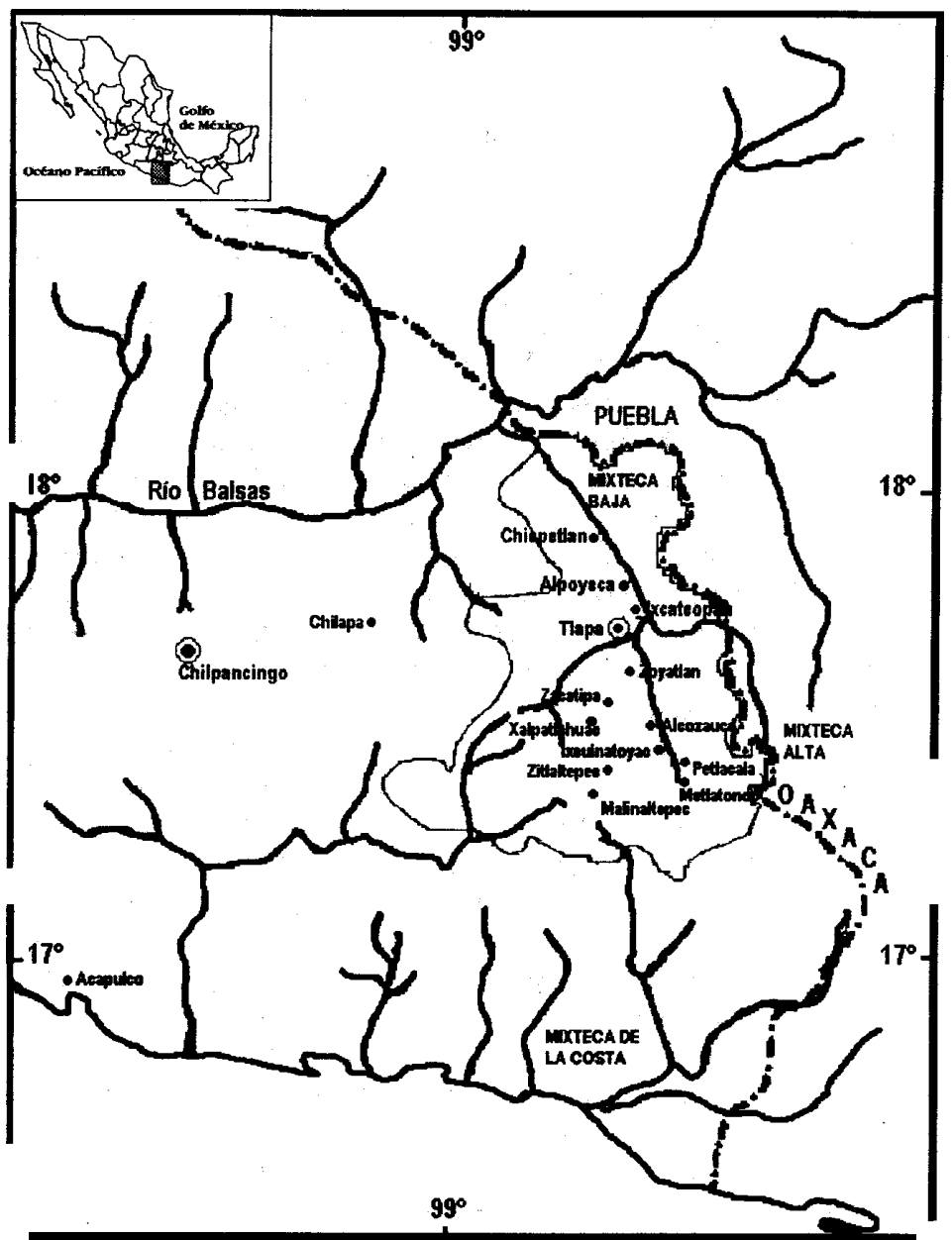

ejercen también gran influencia en la degradación del ambiente en La Montaña de Guerrero. No obstante, de analizarse de manera lineal las relaciones entre los factores socioeconómicos y los problemas ecológicos, muy probablemente se llegaría a generalizaciones poco válidas, dado que el problema ambiental de la región tiene múltiples componentes con interrelaciones complicadas.

\section{Evaluación del deterioro ambiental}

En una primera fase de la investigación se estimó el estado de los recursos naturales a nivel regional por medio de sensores remotos, en las diferentes condiciones climáticas reconocidas (Landa, 1992). Se identificaron los usos del suelo en los distintos sistemas geomorfológicos de cada clima, además de las principales áreas afectadas por erosión y desmonte.

Posteriormente, a nivel de comunidades campesinas se caracterizó igualmente el uso de suelo de 23 localidades ubicadas en los principales ambientes de La Montaña y en distintas regiones agroproductivas. Se utilizaron sensores remotos (fotos aéreas e imágenes de satélite) y se realizaron muestreos de campo para contar con parámetros comparativos y detectar tendencias temporales de cambio en el uso de suelo y la vegetación (Landa, 1992; Mur, 1996; González, 1996).

En las dos escalas de aproximación, cada uno de los elementos describió diferentes aspectos de la degradación de la tierra, y en conjunto permitieron observar más claramente el deterioro en la región.

Con la información recabada de los sensores remotos se describió al ambiente de acuerdo con los diferentes grados de intervención humana. En una primera clasificación se separó a las áreas no deterioradas de las deterioradas. Las primeras se definieron como aquellas en las que los efectos de las actividades humanas son poco conspicuos o vagamente percibidos, y en las cuales la cobertura vegetal mantiene su estructura básica. Las áreas deterioradas, en cambio, presentaban una influencia humana notable, principalmente detectada por la falta de vegetación original (nativa). Posteriormente, las áreas deterioradas se clasificaron en dos categorías generales: daño y alteración.

Dentro de la primera categoría se incorporaron aquellas áreas con erosión severa, muy difíciles de rehabilitar. Por el estado en que éstas se encontraron, no forman parte de los procesos productivos. 

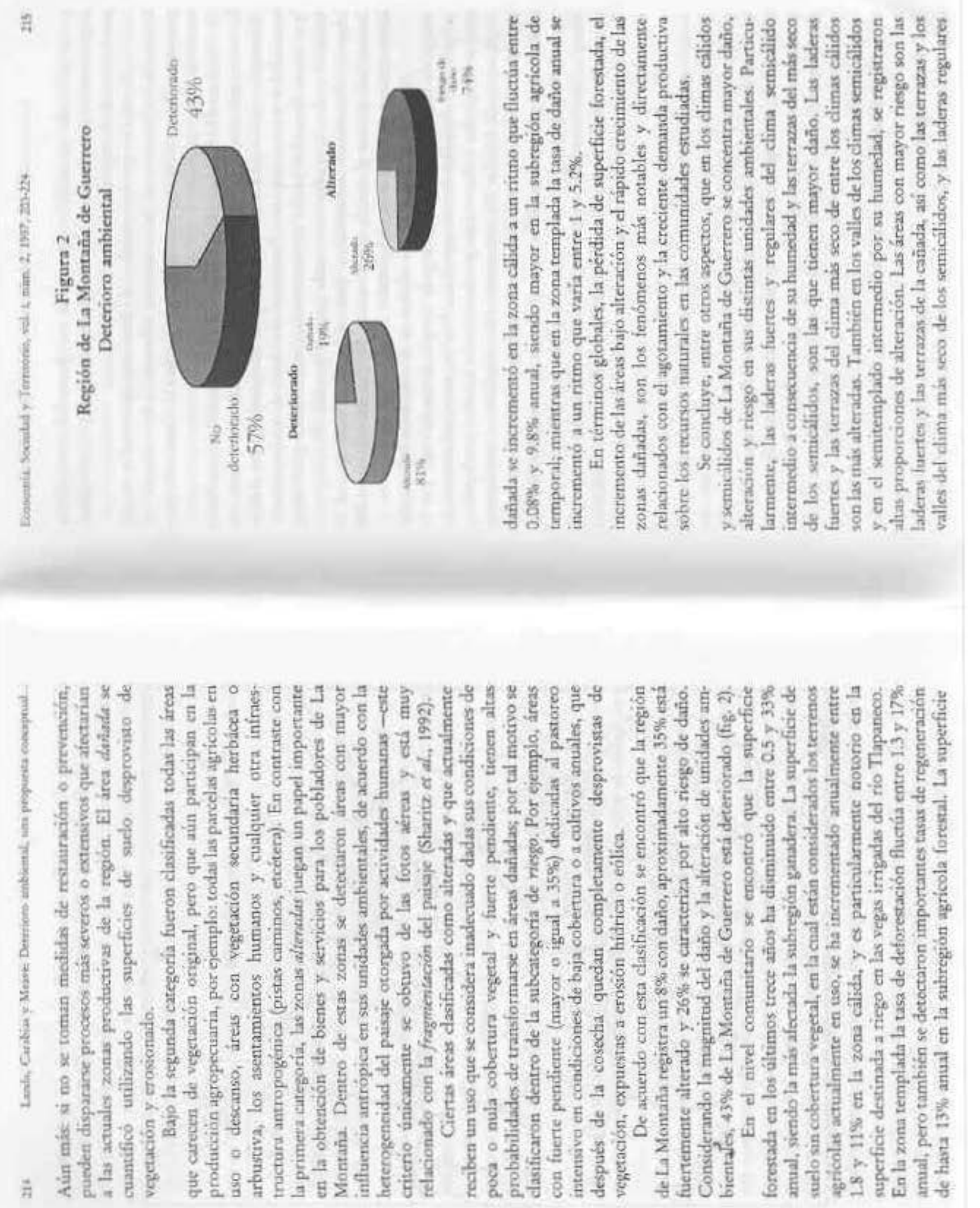
y los valles del semicálido intermedio por humedad. Esto cobra importancia por tratarse de las zonas con mayor actividad productiva de la región.

Como se puede apreciar, el deterioro del medio en La Montaña de Guerrero se da de manera diferencial, dependiendo en principio de condiciones naturales y del tipo de sistemas productivos.

Los diferentes grados de deterioro encontrados responden a la heterogeneidad natural de la región, la cual se traduce en diferencias en el potencial productivo. Por ejemplo, los climas semicálidos y semitemplados favorecen el cultivo de maíz, en tanto que otros climas templados con mayor humedad tienen problemas edáficos y de topografía inadecuada para la producción, así como mayores superficies conservadas. Esto se puede relacionar con la intensidad de uso y con la marginación, lo cual se reflejó en los diferentes grados de alteración y daño.

Asímismo, en los climas cálidos de la zona baja hay mayor riesgo de sequía, pero son aptos para la agricultura de riego por la proporción de valles en su superficie. Por su parte, en la zona de climas templados la desventaja productiva son las altas pendientes y la presencia de heladas. De esta manera las condiciones de relieve y altitud también reflejarondiferencias en la disponibilidadde recursos naturales, y por lo tanto, diferentes grados de deterioro ambiental.

Se sugiere que las zonas templadas son las de mayor marginación, comparadas con las de climas cálidos, lo que podría estar relacionado con la diversificación productiva de estos climas, la forma de uso de los recursos, y el grado de daño e intensidad de uso

En el ámbito regional, en La Montaña el mayor uso no se asoció necesariamente con el daño a la tierra, pero sí con el incremento del riesgo de daño. Ahora bien, si el mayor uso no siempre corresponde a mayor daño sobre los sistemas naturales, se constata que el tamaño de la población no está directamente ligado al deterioro, sino que existen otros factores tales como el tipo de uso y niveles de vida, que podrían formar parte de la dinámica del deterioro ambiental (Landa, 1992).

\section{Concepto de deterioro ambiental}

Definir la degradación de la tierra considerando sólo los aspectos físico-bióticos, puede llevar a la sobresimplificación del problema.

Una definición completa de deterioro ambiental debe tomar en cuenta la pérdida de propiedades en los sistemas naturales vinculada con fenómenos naturales y con actividades humanas, así como aspectos sociales relacionados con el decremento en la disponibilidad de bienes y servicios. De acuerdo con la caracterización de la degradación de la tierra en la región de La Montaña de Guerrero, es imposible caracterizar este proceso con un solo factor. El deterioro ambiental se define entonces como el resultado de la interacción de elementos naturales y humanos ligados con la modificación del ambiente en el sentido de pérdida de sus cualidades, y expresado finalmente como un decremento de bienes y servicios a las poblaciones humanas. Tales elementos son el daño por erosión, el alto grado de alteración e influencia antrópica, y la susceptibilidad a la degradación en diferentes condiciones ambientales (Landa Meave y Carabias, 1997). Cabe aclarar que en la noción de "bienes" se incorporan los llamados bienes ambientales, como podría ser la diversidad ecológica de todo tipo.

La diferencia de esta última definición con la de deterioro ecológico discutida anteriormente, consiste en que en la degradación biológica se concibe al ser humano en la medida en que incorpora actividades modificadoras de la energía que utilizan los organismos para su adecuación, pero no como un elemento del ambiente que rambién puede ver mermados los satisfactores que obtiene de la naturaleza. Aunque teóricamente la cuestión ecológica incluye aspectos socio-ambientales, la falta de criterios humanos al hablar de deterioro ambiental es producto de un desarrollo de las ciencias naturales desvinculado del contexto socioeconómico.

Consideraciones finales

Con el desarrollo de la investigación se logró plantear un método con el que es posible estimar el deterioro ambiental en el curso del tiempo. Los datos obtenidos son descriptivos y útiles para determinar condiciones que indiquen deterioro; lo más importante fue la agrupación de datos y los criterios que se tomaron en cuenta para su análisis e interpretación. En este sentido, el riesgo y el cambio en el tiempo pueden considerarse como los indicadores más adecuados para evaluar deterioro, pero también, como los que requieren de mayor precisión y análisis.

Es básico tener datos sobre la profundidad de suelo, así como relacionar las características de cobertura con la información 
litológica de la región. Ambos aspectos servirían para profundizaren la explicación de riesgos naturales y para conocer si se incrementan o no a consecuencia de la actividad humana.

En este trabajo se relacionó al deterioro con suelo desprovisto de vegetación, erosión, uso y riesgo; no obstante, habría que tener información sobre la productividad de algunos sistemas naturales y antrópicos, sobre la degradación del suelo de las unidades y sobre el potencial forestal, entre otros criterios, para complementar la caracterización del deterioro. Es decir, hace falta un estudio regional de los procesos de deterioro derivados de la intensificación tecnológica (agropecuaria), y que no necesariamente se reflejan en cambios en los patrones espaciales de uso de suelo y vegetación.

El análisis se hizo desde un punto de vista general de aquello que se considera deterioro, pero no se tomó en cuenta la perspectiva del productor campesino, quien quizás obtenga más beneficios de un pastizal que de la vegetación secundaria También es evidente que se prefiere aumentar la superficie agrícola, lo que no necesariamente está ligado a daño, pero sí ocasiona alteración e incrementa el riesgo al daño.

Se aclara conceptualmente la idea de deterioro; se propone y aplica un método de evaluación espacio-temporal que da suficiente información físico-biótica, la cual representa una propuesta viable para unificar métodos y escalas de estudio del deterioro en zonas rurales. Con todo esto se avanza significativamente en el diagnóstico del funcionamiento del sistema, que es parte importante de un análisis socio-ambiental.

Aunque con dicho diagnóstico del sistema no se resuelve el problema de degradación de la tierra, la investigación brinda información suficiente y necesaria para formular propuestas de manejo de recursos en la región encaminadas hacia el desarrollo sustentable.

En lo futuro se esperaría que una caracterización completa de deterioro ambiental incluyera diferentes escalas espaciotemporales, así como la dimensión socioeconómica, y de manera ideal, la generación-de indicadores objetivos y confiables con los cuales estimar la sustentabilidad; por supuesto, en combinación con otras variables del desarrollo humano. Pero un entendimiento total de la dinámica del deterioro en cualquier región, sólo se logrará con la integración del conocimiento por medio del trabajo interdisciplinario.

\section{Bibliografía}

Aizen, A. M. y P. Feizinger (1994), "Habitat Fragmentation, Native Insect Pollinators, and Feral Honey Bees in Argentine 'Chaco Serrano'", Ecological Applications, núm. 4, pp. 378392.

Arizpe, L., M. P. Stone y D. C. Major (eds.) (1994), Population and Environment. Rethinking the Debate, Boulder, Colorado, Westview Press.

Arrhenius, E. (1992), "Population, Development and Environmental Disruption -An Issue on Efficient Natural-Resource Management", AMBIO, vol. XXI, núm. 1, pp. 7-11.

Beltrán, E. (1971), La deterioración ambiental, enfoque ecológico, México, IMERNAR.

Bilsborrow, R. E. (1993), "Reflexiones metodológicas sobre las interrelaciones entre procesos demográficosy problemasdel ambiente en áreas rurales de América Latina", en H. Izazola, y S. Lerner (comps.) (1993), Población y ambiente, ¿̇nuevas interrogantesa viejosproblemas?,México, SOMEDE-E1Colegio de México-The Population Council.

y H. W. O. Okoth-Ogendo (1992), "Population-Driven Changes in Land use in Developing Countries", AMBIO, vol. XXI, núm. 1, pp. 36-45.

y P. DeLargy (1991), "Land Use, Migration and Natural Resource Deterioration: The Experience of Guatemala and The Sudan", en K. Davis y M. S. Bernstam (eds.) (1991), Resource and Environment Population: Present Knowledge, Future Options, Oxford, Oxford University Press.

Blaikie, P. y H. Brookfield (1987), Land Degradation and Society, Londres, Methuen and Co.

Bojo, J. P. (1991), “Economics and Land Degradation ${ }^{\mathrm{n}}$, AMBIO, vol. XX, núm. 2, pp. 75-79. 
Bolaños, F. (1990), El Impacto Biológico, problemia ambiental contemporáneo, México, Instituto de Biología/Universidad Nacional Autónoma de México.

Boserup, E. (1981), Population and Technological Change: A Study of Long-term Trends, Chicago, University of Chicago Press.

Pradshaw, A. P., D. A. Goode y E. H. P. Thorp (1986), Ecology and Design in Landscape, Londres, Blackwell.

Browne, S. (1982), "The Environment of Poverty", en M. Hufschmidt y E. L. Hyman (eds.), Economic Approach to Natural Resource and Environmental Quality Analysis, Dublin, Tycooly Int. Pub. Limited.

Carabias, J., E. Provencio y C. Toledo (1994), Manejo de recursos naturales y pobreza rural, México, Universidad Nacional Autónoma de México-Fondo de Cultura Económica.

CEPAL/ClADES (1981), Tesauro del Medio Ambiente para América Latina y El Caribe, Santiago de Chile, CEPAL.

Chokor, B. A. y S. A. Mene (1992), "An Assessment of Preference for Landscapes in the Developing World: Case Study of Warri, Nigeria, and Environs", Journal o Environmental Management, núm. 34, pp. 237-256.

Committee on the Applications of Ecological Theory to Environmental Problems (1986), Ecological Knowledge and Environmental Problem-solving; Concepts and Case Studies, Washington, D. C., National Academy Press.

Cruz, M. C. et al. (1992), Population Growth, Poverty and Environmental Stress: Frontier Migration in the Philippines and Costa Rica, Washington, D. C., World Resource Institute.

Dasgupta, P. (1992), "Population, Resources and Poverty", AMBIO vol. XXI, núm. 1, pp. 95-101.

Davis, K. (1991), "Population and Resources: Fact and Interpretation", en K. Davis y M. S. Bernstam (eds.) (1991),
Resaurce, Environment and Population: Present Knowledge, Future Options, Oxford, Oxford University Press.

Ehui, S. K. y T. W. Hertel (1992), "Testing the Impact of Deforestation on Aggregate Agricultural Productivity", Agricultural, Ecosystems and Environment, núm. 38, pp. 205 -

Falkenmark, M. y R. A. Suprapto (1992), "Population-Landscape Interactions in Development: A Water Perspective to Environmental Sustainability", AMBIO, núm. 21, pp. 30-35.

Forman, R. T. y M. Godron (1981), "Patches and Structural Components for a Landscape Ecology", Bioscience, núm. 31, pp. $733-740$

_- (1984), "Landscape Ecology Principles and Landscape Function", en IALE, First International Seminar on Methodology in Landscape Ecological Research and Planning (Memoria), vol. sup., Dinamarca, pp. 4-15.

Fox, J. (1992), "The Problem of Scale in Community Resource Management", Environmental Management, núm. 16, pp.
289-297.

García-Barrios, R., L. Garcia-Barrios y E. Álvarez-Buylla (1991), Lagunas: deterioro ambiental y tecnológico en el campo semiproletarizado, México, El Colegio de México.

Glantz, M. H. (ed.) (1977), Desertification, Boulder, Colorado, Westview Press.

Graham, O. P. (1992), "Survey of Degradation in New South Wales, Australia", Environmental Management, núm. 16, pp. 205-223.

González, C. C. (1996), Cambios de uso del suelo y deterioro ambiental en ,comunidades campesinas en la región de $\mathrm{La}$ Montaña de Guerrero, México, Facultad de Ciencias/Universidad Nacional Autónoma de México, tesis profesional. 
Helldén, U. (1991), "Desertification - Time for an Assessment?", AMBO, núm. 20, pp. 372-383.

Izazola, H. y S. Lerner (comps.) (1993), Población y ambiente, inuevas interrogantes a viejosproblemas?, México, SOMEDE-E1 Colegio de México-The Population Council.

Jean, M. y A. Bouchard (1991), "Temporal Changes in Wetland Landscapes of a Section of the St. Lawrence River, Canada", Environmental Management, núm. 15, pp. 241-250.

Kim, O. y P. van den Oever (1992), "Demographic Transition and Patterns of Natural-Resources Use in The Republic of Korea", AMBO, núm. 21, pp. 56-62.

Landa, R. (1992), Evaluación regional del deterioro ambiental en La Montaña de Guerrero, México, Facultad de Ciencias/Universidad Nacional Autónoma de México, tesis de grado.

, J. Meave y J. Carabias (1997), "Environmental Deterioration in Rural Mexico: An Examination of the Concept", Ecological Applications, núm. 7, pp. 316-329.

Le Tacon, F. y J. Laker (1990); "Deforestation in the Tropics and Proposals to Arrest it", AMBO, núm. 19, pp. 372-378.

Lira, J. et al. (1992), "A Probabilistic Model to Study Spatial Variations of Primary Productivity in River Impoundments", Ecological Applications, núm. 2, pp. 86-94.

Martínez, R. M. y J. R. Obregón (1991), La Montaña de Guerrero: economía, historia y sociedad, México, Instituto Nacional Indigenista y Universidad Autónoma de Guerrero (Serie Economía y Sociedad, núm. 1)

McGovern, T. H. et al. (1988), "Nonhern Islands, Human Error, and Environmental Degradation: A View of Social and Ecological Change in the Medieval North Atlantic", Human Ecology, núm. 16, pp. 225-27.

Mehrotra, A., V. K. Yadav y J. Adinarayana (1991), "Temporal Changes of Vegetal Cover in Indian Semi-arid Tropics
Through Landsat Images", Journal of Environmental Management, núm. 32, pp. 35-43.

Mladenoff et al. (1993), "Comparing Spatial Pattern in Unaltered Old-growth and Disturbed Forest Landscapes", Ecological Applications, núm. 3, pp. 294-306.

Mur, F. P. (1996), Caracterización del deterioro ambiental en comunidades rurales de la región de La Montaña de Guerrero, México, Facultad de Ciencias/Universidad Nacional Autónoma de México, tesis de grado.

Myers, N. (1992), "Population/Environment Linkages: Discontinuities Ahead $^{\mathrm{n}}$, AMBIO, núm. 21, pp. 116-118.

Naveh, Z. y A. S. Lieberman (1984), Landscape Ecology, Theory and Application, Nueva York, Springer-Verlag.

Noss, R. F. (1987), "From Plant Communities to Landscape in Conservation Inventories: A Look at the Nature Conservancy in USA", BiologicalConsewation, núm. 41, pp. $11-37$

Olsson, K. y A. Rapp (1991), "Dryland Degradation in Central Sudan and Conservation for Survival", AMBIO, núm. 20, pp. 192-195.

Ortiz, S. M., M. Anaya y J. W. Estrada (1994), Evaluación, cartografía y políticas preventivas de la degradación de la tierra, México, Colegio de Posgraduados, Universidad Autónoma de Chapingo-Comisión Nacional de Zonas Áridas.

PAIR (1992), Elementos para la incorporación de criterios ambientales a la planeación regional en La Montaña de Guerrero, Santiago de Chile, Programa de Aprovechamiento Integral de Recursos Naturales, Facultad de Ciencias/Universidad Nacional Autónoma de México-CEPAL-Gobierno del Estado de Guerrero.

Pearce, D. (1990), "Población, pobreza y medio ambiente", Pensamiento Iberoamericano, núm. 18, pp. 223-258. 